\title{
«La lectura de los que nada leen». Prensa periódica y lectura en el siglo XIX
}

\section{«The reading of those who don't read a thing». Periodical press and reading in the Nineteenth Century}

\section{Hernán Pas ${ }^{1}$}

Universidad Nacional de La Plata (UNLP), Instituto de Investigaciones en Humanidades y Ciencias Sociales (IdIHCS), Consejo Nacional de Investigaciones Científicas y Técnicas (Conicet), Argentina

\section{RESUMEN}

A diferencia de las líneas dominantes en la mayoría de los estudios sobre prensa en el siglo XIX — que suelen abordar el fenómeno de las publicaciones periódicas bajo el paradigma de las identidades nacionales - , nos proponemos con este trabajo avanzar en una caracterización de modalidades y prácticas de lectura ( $y$, por ende, de escritura) vinculadas a la dinámica y a la materialidad del impreso periódico. De este modo, también procuramos ajustar los postulados de la nueva historia del libro acerca de las prácticas lectoras a un universo específico, el del periódico, que en los estudios más conocidos de esta escuela en general suele ser subestimado.

\section{PALABRAS CLAVE}

Prensa periódica, lectura, lectores, siglo XIX

\section{ABSTRACT}

Unlike the dominant lines of the studies on periodical press in the 19th century - which often approach the phenomenon of the periodical press under the paradigm of

\footnotetext{
1 Licenciado, profesor y doctor en Letras por la Universidad Nacional La Plata, e investigador del Consejo Nacional de Investigaciones Científicas y Técnicas (Conicet). Docente de Literatura Argentina I en la Facultad de Humanidades y Ciencias de la Educación (UNLP). Es autor de varios trabajos sobre literatura y cultura en el siglo XIX y de los libros Ficciones de extranjería (2008), Sarmiento, redactor y publicista (2013) y El romanticismo en la prensa periódica rioplatense y chilena. Ensayos, críticas, polémicas (2014), de acceso libre en: http:// bibliotecaorbistertius.fahce.unlp.edu.ar/
} 
the national identities-, we propose with this work to advance in a characterization of modalities and practices of reading (and, therefore, of writing) linked to the dynamics and to the materiality of the periodical press. Thus, we also try to fit the postulates of the new history of the book it brings over from the reading practices to a specific freedom, that of the newspaper, which in the most renowned studies of this school is in general usually underestimated.

\section{KEYWORDS}

Periodical press, reading, readers, nineteenth century

\section{Introducción}

Las tendencias de los estudios de la prensa periódica de los últimos años, y sobre todo de los dedicados al mercado editorial del siglo XIX, han priorizado el rol de la prensa, bien en la formación de los espacios públicos nacionales o bien en la formación de nuevos públicos lectores, en particular con la floración del impreso que se produce hacia el último cuarto de siglo, y la incidencia transformadora que esa expansión supuso para los cánones literarios dominantes.

De manera un tanto paradójica, en ambos casos el periódico sigue ejerciendo de elemento subsidiario: del discurso político, de un lado, del literario o libresco, del otro. En efecto, a pesar del renovado interés de la nueva historia cultural por las prácticas lectoras, en la mayoría de las aproximaciones al fenómeno de la lectura - y de la escritura (Lyons, 2001, 2012; Martin, 1994; Chartier, 1994; Cavallo y Chartier, 2001) - el soporte dominante sigue siendo el libro, como si la práctica de la lectura - como si su historización - estuviera intrínsecamente vinculada al formato codex. Así, en el siglo de la prensa, el impreso periódico sigue funcionando como elemento amplificador, trasmisor y vulgarizador de un fenómeno, la lectura, que se consagra previamente en el libro.

En el espacio acotado de este trabajo propongo discutir tres ejemplos representativos de lo que podríamos considerar, glosando un título del profesor español Emilio Torné (2001), la prensa como máquina de lectura. El término máquina, aquí, procura captar al menos dos resonancias teóricas. Por un lado, la idea de una tecnología relativamente sofisticada cuya medular característica reside en su capacidad de (re)mediación. El concepto de remediación [remediation] es utilizado por Bolter y Grusin para significar aquello que McLuhan había señalado como contenido específico de los media, es decir, «la representación de un medio en otro medio» (Bolter y Grusin, 2000, p. 45). Una muestra clave de remediación 
en la prensa periódica es la apelación temprana y constante - como veremos en algunos de los ejemplos aquí analizados - al género epistolar, al punto que podría pensarse como una extensión pública — como un afán de inmediatez- del género por la tipografía.

Por otro lado, esa tecnología mediática nos recuerda, siguiendo la línea abierta por la bibliografía textual o material inaugurada por D. F McKenzie (1985), que la lectura se compone de texto y objeto, que las formas afectan los sentidos y que, por último, las prácticas lectoras se definen siempre en relación necesaria con esas formas².

En lo que sigue, procuraremos entonces indagar las posibilidades de lectura abiertas por el periódico —ese medio novedoso para la época- en tres momentos diversos de la prensa rioplatense. Si bien nuestras reflexiones se ciñen a un campo específico, el de la prensa y la cultura letrada argentinas, no faltarán ejemplos comparativos de otras regiones; por lo demás, al colocar al periódico como elemento privilegiado de nuestro análisis, aspiramos a que la validez de nuestras hipótesis o inferencias puedan corroer el estrecho marco — tan legitimo y enriquecedor en otro casos - de las fronteras nacionales, a fin de poder pensar el objeto periódico como un artefacto cultural de alcance transnacional.

\section{Leer con gusto}

El 7 de julio de 1821, en un momento caracterizado por un incipiente estado de regularidad institucional con la vuelta del general Martín Rodríguez al gobierno, El Argos de Buenos Aires —una de las publicaciones más representativas del periodo, que había comenzado a publicarse apenas dos meses antes - anunciaba complacientemente la aparición de otro periódico, El Curioso, al cual decía suscribirse con entusiasmo:

Se ha publicado el Prospecto de un periódico que una sociedad ofrece dar semanalmente por la imprenta de los expósitos, titulado El Curioso, Periódico Científico-Literario-Económico [...]. El Argos, sin haber sido invitado por nadie, no puede menos que recomendar a sus paisanos la importancia de aquel papel, si guarda, como lo espera, consonancia con su título. Él se suscribe desde luego... (El Argos de Buenos Aires, nro. 9, 7 de julio de 1921).

¿Cuál era la importancia que ese título ameritaba según los redactores de El Argos? En principio, hay que notar que, en el contexto brevemente descrito, la aparición de una publicación destinada a los intereses que ostentaba el sublema «científico-literario» era por aquellos años una

2 En palabras de Donald McKenzie (1985, p. 20): «New readers of course make new texts, and that their new meanings are a function of their new forms». Ver Torné, 2001, p. 151. 
novedad y comenzaría a dejar de serlo avanzada la década siguiente. La propuesta buscaba entonces abarcar un espectro de lectura más amplio que el dominado por las ideologías del ciclo independentista, es decir, buscaba interpelar una franja del lectorado que las plataformas retóricas de los periódicos noticiosos y políticos hasta entonces no contemplaban, estrategia de lectura que con el correr de los años se haría cada vez más frecuente. En segundo lugar, el título buscaba significar el asiento institucional de sus redactores, dado que El Curioso nacía como órgano de la Sociedad Secreta Valeper, una de las tempranas asociaciones literarias de Buenos Aires. Pero quizás el motivo más importante radique en la apelación de ese periódico al orbe de las curiosidades que, como ha propuesto recientemente Víctor Goldgel (2013, pp. 89 y ss.), significaba la aceptación de un público lector más variado, atento más a lo novedoso o entretenido que a la discusión doctrinaria o política. Este es el aspecto que, en su primer número, el periódico parece asumir al resaltar, por un lado, «la singular benignidad con que nos ha acogido el público», y, por otro, confesar: «En verdad no conocíamos la actual metamorfosis del gusto del país; no esperábamos tanto» (El Curioso, nro. 1, p. 4).

El periódico tuvo corta vida (alcanzó apenas los cuatro ejemplares), síntoma quizás de una receptividad no del todo consolidada. No obstante, la susodicha «metamorfosis» de la que habla El Curioso en ese suelto no debería ser pensada tanto como cambio o mudanza en los intereses del público lector, sino más bien como la emergencia o visibilidad de tales intereses que una auspiciosa dialéctica del intercambio — antes reducida a los ejercicios fabulescos del régimen de privilegio, como enseguida veremos- ahora, en cambio, hacía posible. En este sentido, Antonio Cornejo Polar apuntaba hace ya un par de décadas la necesidad de atender, en el marco de las nacientes repúblicas, a la formación de un nuevo público «no porque sea definidamente distinto o más vasto que el colonial, sino porque negocia otra articulación con la literatura a la que exige condiciones hasta entonces inéditas» (Cornejo Polar, 1995, p. 13).

Para inducir una aproximación a ese nuevo pacto de lectura resulta oportuno repasar la fábula en verso que EI Curioso publica en su tercer número, ocupando toda la primera página y buena parte de la segunda. En forma de diálogo versificado, se representa en el periódico la escena de un acto de lectura en el que una niña aparece leyendo ciertos «secretitos de hermosura» mientras su madre la reconviene para que se incline a tareas conformes a su edad, pero sobre todo a su sexo:

Vieja: Deja muchacha ese papel: no quiero que leas esas cosas. Vete al punto al aposento y toma el costurero. 
Niña: Pero mi madre ¿acaso (yo pregunto) de lo que aquí he leído hay diferencia a lo que se nos dice todo el día? [...]

Niña: Yo a esto leo con gusto, y me contento [...] en los triunfos que obtiene la belleza: lo demás no me importa [...]

De mi solo interés y cuidado son ciertos secretitos de hermosura que el Curioso galán nos ha apuntado ¡Quién creyera!, mi tía: hay una untura Que causa un blanqui-rojo primoroso.

Vieja: Calla muchacha: esa es una locura; ¡Vaya que es un bribón el tal Curioso!

Niña: Si lo ha hecho, tía mía, la Anastasia; ¿No la vio V. ayer? De tan hermoso Rostro jamás ha sido; aunque su gracia De toda la tertulia es aplaudida. Una opiata de célebre eficacia:

Para los dientes. La agua encarecida De virginal belleza... ¡Soberanas Cosas! Yo estoy con ellas aturdida; Secreto para hacer negras las canas...; Pero esto de saber no solicito, que es para las matronas ancianas...

Vieja: Haber (sic) hijita, léeme ese puntito... (El Curioso, nro. 3, p. 1).

Este diálogo ejemplifica la convivencia de dos órdenes culturales superpuestos: por un lado, la circulación del periódico indica una nueva práctica de lectura, accesible y cotidiana, al alcance de la mano de una «niña»; por el otro, la «vieja» comadrona reproduce la visión patriarcal heredada de la Colonia: la niña no debe leer (menos un periódico), sino «tomar el costurero». La escena presenta previsiblemente esa estratificación en términos genéricos. Muestra, al identificar a la niña con la sección de misceláneas del impreso, la diversificación de los objetos de lectura así como la propia naturaleza diversificada del registro periodístico. Por lo demás, los «secretitos» del periódico seducen: la «vieja», finalmente, termina prendada de su lectura. 
Pero lo más interesante de esta tirada de versos tal vez radique en la representación del hecho mismo de la lectura. En estas páginas no solo se pone en juego la controversia entre dos puntos de vista, o dos modelos culturales, sino que también se escenifica el fenómeno de la lectura, en este caso un tipo de lectura cuya novedad - la actualidad del «estar a la dernière», como diría en El Progreso de Sarmiento un anónimo colaborador - radica en la multiplicidad de objetos que el impreso ofrece ante los ojos de la niña: «Una opiata de célebre eficacia: / Para los dientes. La agua encarecida / De virginal belleza... [...]; / Secreto para hacer negras las canas». Como si estuviesen extractando una página de avisos, que empezarían a hacerse frecuentes hacia el final de esa misma década, los versos reproducen una lectura fraccionada, que avanza por temas o títulos, gozosa de su propia displicencia, acorde a la superficie tipográfica en la que los mismos versos se insertan.

Para observar la contraparte de este tipo de lecturas se podría citar una buena cantidad de textos periodísticos en los que sus redactores reflexionan acerca de la necesidad de atender a esa multiplicidad de intereses, como por ejemplo el que escribiera Juan María Gutiérrez en El Recopilador, de 1836, en el que, muy tempranamente si pensamos en el desarrollo de la prensa a nivel mundial, sostenía: «Lo primero que tiene en vista $E l R e$ copilador es la variedad, el contraste en los artículos de sus columnas; sin esta condición, difícil o imposible es ser leído en los tiempos presentes» (El Recopilador, Buenos Aires, 1836, pp. 121-123). Los «tiempos presentes» sobre los que reflexiona Gutiérrez no son otros que los de la prensa, con sus breves y efímeras incursiones temáticas, sus propagaciones científicas y tecnológicas, sus variopintas técnicas de mediación, su afán enciclopédico, su impulso antológico y a la vez sintético ${ }^{3}$.

No obstante, prefiero plantear un recorrido inverso y reponer un momento en el que la prensa periódica no posee aún posibilidades técnicas para expandir ese registro. Me refiero a la prensa llamada tardo-colonial, es decir, a los periódicos que se imprimían y circulaban bajo el sistema de privilegio o, como solía aparecer estampado al pie de ese tipo de impresos, «Con Licencia del Real Superior Gobierno» u otra variante similar. A medida que avancemos, comprobaremos que esa imposibilidad no necesariamente es indiciaria de una monotonía o de un reducido espectro en el gusto de los lectores. Al contrario, las tensiones y estrategias publicitarias, aun en su acotado despliegue, nos mostrarán — negativamenteuna diversidad latente, embrionaria, cuyo alcance buscan interpelar esos

3 En su reciente libro, V. Goldgel (2013, pp. 83-108) da sobrados ejemplos sobre el asunto. 
mismos impresos. Al hacerlo, la interpelación devela su reverso: la inscripción formal de los sociales intereses de lectura.

\section{La variedad soterrada}

Entre abril de 1801 y junio de 1810 en que apareció la célebre Gazeta de la Junta de Moreno, se publicaron en Buenos Aires de manera sucesiva tres periódicos que, por su temática, sus rasgos formales y tipográficos, sus modalidades de circulación y sus propuestas editoriales pertenecen a un mismo universo letrado y discursivo: el de la publicidad ilustrada coIonial. Ellos son: el Telégrafo Mercantil. Rural, Político, Económico e Historiográfico del Río de la Plata (de abril de 1801 a octubre de 1802), el Semanario de Agricultura, Industria y Comercio (de agosto de 1802 a febrero de 1807) y el Correo de Comercio (de marzo de 1810 a abril de 1811) 4

En términos generales, los tres periódicos conforman una empresa pedagógica y propagadora del conocimiento, de modo que asumen implícita o abiertamente el carácter filantrópico con que fue pensada durante mucho tiempo la prensa: como expansión de las Luces ${ }^{5}$. El declamado destinatario principal de estas publicaciones lo conformaban dos clases de lectores: comerciantes y labradores, aunque, por los comentarios y reclamos de los redactores, puede aseverarse que la principal audiencia imaginada por estos periódicos es la de los trabajadores rurales.

Dado el sistema imperante del privilegio ${ }^{6}$, estos impresos funcionan bajo dominio de un redactor principal y único y con el filtro de la censura previa, lo que los vuelve discursivamente más unívocos. No obstante, como ocurre con otros periódicos de la misma época de otras ciudades virreinales como el Mercurio Peruano (1791-1795) o el Papel Periódico de La Havana (1790-1805), los redactores recurren al género epistolar — que, cabe apuntar aquí de paso, como han demostrado varios estudios recientes, funciona en la confección de noticias como marca de autenticidad discursiva, en tanto las cartas oficiaron el pasaje de la esfera de lo íntimo, y del nombre propio, a la de la publicidad anónima ejercida por el impreso

4 Los tres periódicos fueron publicados por la célebre Imprenta (Real, por entonces) de los Niños Expósitos. Compartieron, además, algunas de las plumas que colaboraron en la redacción y que luego se destacarían en los episodios revolucionarios (por ejemplo, Castelli, Paso, Belgrano). El Telégrafo fue redactado por Francisco Antonio Cabello y Mesa, y alcanzó al parecer la suma de 237 suscriptores. El Semanario fue redactado por Juan Hipólito Vieytes, y recibió la ayuda de Pedro A. Cerviño, entre otros. El Correo del Comercio apareció el 1 de marzo de 1810, embebido de las ideas independentistas y a cargo nada menos que de Manuel Belgrano, a quien secundó el redactor del extinguido Semanario (Galván Moreno, 1944, pp. 27-51).

5 Una visión de conjunto de estos periódicos puede consultarse en los trabajos recientes de Pablo Martínez Gramuglia (2010, 2012). Ver las referencias bibliográficas.

6 Me refiero al sistema de «patronato» y privilegio, según el cual la autoridad real era la única que dispensaba la legitimidad de cualquier publicación durante el Antiguo Régimen. 
(Brownless, 2016, p. 411) - para poner en discusión una serie de temáticas que, de otro modo, no tendrían la legitimidad social que esos intercambios fingidos virtualmente buscaban otorgarle ${ }^{7}$. De modo similar a como lo hacían los redactores del Mercurio Peruano y del Papel Periódico de La Havana, o a como lo hacían los redactores de la Gaceta de Caracas, cuyas correspondencias fueron estudiadas por Christopher Conway (2006, pp. 77-91) en sus diferentes etapas entre la Colonia y los vaivenes de la Independencia, los periódicos rioplatenses apelaron al formato del remitido o de la carta para, en primer orden, canalizar sus inquietudes respecto de la captación del público y, en segundo lugar, socializar asuntos bajo la máscara del anonimato, dado que la mayoría de las cartas aparecían — previsiblemente - o bien firmadas con seudónimo o bien anónimas. ${ }^{8}$

Se trata, por cierto, de una escenificación, de una ficción de lectura que, tal como mostró Annick Lempérière (1998, pp. 54-79), resultó decisiva para la construcción de una novedosa opinión pública que cobraría mayor impulso con los sucesos de la Independencia. Una escenificación, cabría agregar, cuyo protocolo de lectura se aproxima a la vez que se distancia de otra puesta en escena de la voz popular, de gran trayectoria en el Río de la Plata: me refiero a la gauchesca, cuyo juego dialéctico entre escritura y oralidad ha sido revisado magistralmente por Julio Schvartzman en sus recientes Letras gauchas (2013) ${ }^{9}$.

7 Un dato para destacar de estas publicaciones, además de que funcionaban bajo el amparo del patronato, es que la mayoría surge de - o se vincula con - sociedades ilustradas en donde sus discusiones confluyen y de donde suelen extraer material -en ocasiones en forma de cartas, en otras en la modalidad de discursos - para la empresa editorial. Así, por ejemplo, el Telégrafo responde a una iniciativa anterior de la Sociedad Patriótica y Económica de Buenos Aires; el Mercurio Peruano se publicaba bajo auspicio de la Sociedad de Amantes del País, y otro tanto ocurre con el Papel Periódico y el Diario de La Habana, en donde confluyen los intereses de la Real Sociedad Patriótica. Dadas las características aristocráticoletradas que las definen, estas asociaciones permiten que los intercambios (fingidos, o no) entre los redactores y la sociedad civil se legitimen como voz social ante el gobierno.

8 En el Mercurio Peruano son frecuentes las Cartas escritas a la Sociedad sobre temas de interés público, pero también son acogidas cartas o remitidos que buscan incorporar materias de dispersión como la carta firmada por Joseph Ganarrila acompañada de una poesía titulada «Introducción a la historia de los Incas» (9 de setiembre de 1992). En el Papel Periódico de La Havana, la intervención corresponsal se hace altanera y temprana, con juicio crítico mediante. En efecto, desde los primeros números los remitidos cobran el cariz de la crítica y reorientación del periódico, como la «Carta dirigida al Impresor sobre el Papel Periódico número 2», en la que se lee: «Muy señor mío: No es mi ánimo censurar las producciones que V. se toma el trabajo de dar al Público en los Papeles Periódicos que con tanta utilidad se han establecido todas las semanas en la Havana [...]. No hay duda que las noticias literarias son utilísimas en muchos casos, y que los papeles públicos en la Europa dan algunas; pero siempre he observado que son muy extractas, aun en los Mercurios que contienen cien páginas en octavo; y por consiguiente es notable que en un escrito de medio pliego se haga una relación sobre un solo punto que ocupe más de las tres cuartas partes de él» (31 de octubre de 1990).

9 Se aproxima en tanto los lectores u oyentes (o lecto-yentes, según fórmula de J. F. Botrel [1998, p. 586]) que estos impresos buscaban interpelar se ubicaban en la misma franja societal de la gauchesca, esto es, los habitantes rurales; se aleja, sin dudas, de modo rotundo, 
En el prospecto con que el Semanario de Agricultura daba a conocer sus objetivos editoriales, al exponer la novedad de que la «voz del sabio» podía ahora cruzar el Atlántico y desparramarse por el orbe entero - ofreciendo así una sugerente imagen espacial de los alcances de la prensa-, Hipólito Vieytes, su redactor, reconocía que, dado el aislamiento en el que permanecen los trabajadores rurales ${ }^{10}$ :

aun sería casi del todo insuficiente este papel por sí mismo, si el celo conocido de nuestros Párrocos no le diesen todo el valor que le falta para con sus feligreses haciéndoles entender prácticamente todo el pormenor de sus preceptos en aquella parte que diga más en relación a su situación local. ¿Y quién podrá dudar por un instante solo que estos ejemplarísimos Pastores no quieran agregar al peso de sus tareas la de enseñar el camino de salir de la miseria? (Semanario, Prospecto, p. IV).

La apelación a los párrocos para que difundan el contenido del impreso es sin dudas una de las matrices de la cultura letrada tardo-colonial, que confunde -y confundirá largamente- instrucción con evangelización. Este es un aspecto que ha sido bien tratado por Chartier (1993, pp.177195). No obstante, lo que me interesa recuperar aquí es el desajuste entre la propuesta editorial y los virtuales lectores a que estas publicaciones pretenden convocar; desajuste entre cuyas razones habría que ponderar no solo la disputa de autoridad con el saber tradicional de la Iglesia - la posibilidad cierta de que los curas optaran por otro tipo de lecturas para «sus» feligreses, menos científicas y más piadosas—, sino también la ineficacia pragmática de una escritura técnica y farragosa, en particular esta de Vieytes, que se repliega en dilatados periodos y notas a pie postulando, a contramano de sus anhelos de expansión, un lector instruido, más bien libresco.

Apenas un año después, el 1 de junio de 1803, el mismo redactor del Semanario de Agricultura publicaba una serie de quejas a los suscriptores - a la escasez de suscriptores, habría que decir-, quienes, al parecer, no respondían con demasiado entusiasmo a la propuesta de su empresa editorial:

por el tipo de opción por la lengua ejecutada. Otro crítico argentino, Eduardo Romano, había señalado también el uso temprano y modélico del género epistolar en las gacetas populares de Luis Pérez.

10 Escribía, al respecto, Vieytes: «Mientras el ciudadano admira los principios de la más profunda teoría y cotejados a la práctica los encuentra en un todo ajustados y precisos, el pobre habitador de la campaña se mantiene aislado y entregado a sí mismo siguiendo la rutina que aprendió de sus mayores» (Semanario, «Prospecto», p. IV). 
El práctico agricultor ha enmudecido [...]. El hacendado ha guardado un silencio profundo en el manejo económico de sus posesiones rurales. El comerciante ha creído indigno de su atención el presentar un plan de especulaciones arregladas con proporción a los inmensos frutos que produce nuestro suelo. El Párroco... pero confunda mi pluma en el silencio el respetable nombre de los que debiendo ser el instrumento de la felicidad de las campañas, no han querido ocupar un cuarto de hora en leer un pliego de papel con el título de Semanario de agricultura. (Semanario, nro. 37, p. 290).

La queja de Vieytes redundaría en un conflicto de autoridad con la Iglesia - o, dicho con precisión, con sus representantes misioneros- o sobreabundaría en una imagen historiográfica estereotipada de la carencia de lectores y de lectura, no ya, previsible y razonablemente, en el ámbito rural, sino también en la ciudad —la apelación a los comerciantes es sintomática a ese respecto-, a no ser por las evidencias que su propio periódico ofrece respecto de la (aparente) variabilidad de las preferencias de lectura, por más acotadas que estas resulten en lo concreto. Una primera muestra de ello es la presunción que asume el redactor respecto de los motivos de semejante apatía:

Sí, compatriotas - dirá-; cuando hacemos tan poco aprecio de aquel tiempo que malgastamos en leer novelas y romances, sentimos una fuerza irresistible en escuchar el modo como pudieran salir de la opresión y la miseria aquellos hermanos nuestros que llenos de polvo y de sudor trabajan incesantemente en procurar los auxilios de nuestra propia subsistencia (Semanario, ibíd., p. 292).

Como se ve, en un gesto típico de quienes por entonces empalmaban ética del trabajo con moral religiosa - gesto de larga data y que, como se encargaron de demostrar A. M. Chartier y J. Hébrard (1994), perduraría hasta avanzado el siglo XX-, Vieytes condena la lectura de romances, maligna por ociosa, y pretende instalar en su lugar la de su sesudo periódico, útil e instructivo. Así, lo que este tipo de inscripciones en verdad nos está sugiriendo es la posibilidad de que, al menos, en este preciso caso, los lectores encontraran más confortable asilo en textos menos serios o doctrinarios, temáticamente más flexibles.

Una segunda razón para pensar en este sentido son las estrategias desplegadas por el redactor del Semanario: si los párrocos no les leen su periódico a los habitantes rurales, si los comerciantes, terratenientes o milicianos parecen no distinguir el valor de su propuesta, Vieytes se preocupa por ampliar las ofertas de lectura. Así, por ejemplo, en el número subsiguiente el periódico incorpora los Avisos del movimiento portuario -información que claramente apunta a captar el interés de los 
viandantes y comerciantes- ${ }^{11}$. Concomitantemente, el impreso comienza a cargarse de textualidades diversas. La más común y frecuente, como ya mencionamos, era la de la carta. Los remitidos o cartas de lectores comienzan a alternar con los discursos monótonamente agraristas o prácticos - aun respondiendo a esa misma temática, las cartas ofician de leve ruptura en el monocorde discurso del redactor-; así, por ejemplo, las cartas de Mariano Frequeriar, que en el número inmediato posterior al del quejumbroso editorial ya citado, iniciarán su recorrido proponiendo asuntos a publicar, o las de Cipriano Orden Vetoño o Casimiro Chegre, entre otros, que oficiarán como interlocutores - ficticios, desde ya- de esa maleabilidad de los intereses lectores ${ }^{12}$. Asimismo, aparecen en el Semanario cada tanto otro tipo de discursos y géneros, como los extractos de otros impresos o las citas de obras ajenas ${ }^{13}$.

Este incipiente despliegue de lo que tematizaría veinte años después El Curioso y que llegaría a convertirse en plataforma genérica de la prensa de mediados de siglo, esto es, la sección denominada Variedades, nos ofrece algunos indicios para revisar el campo de la lectura en el siglo XIX, en especial la relación entre formatos, demandas y modos de lectura.

\section{La lectura fragmentada}

Otra modalidad de lectura, también fraccionada, que avanza no ya por títulos o emblemas, como en el caso de la niña lectora de El Curioso, sino por capítulos y subcapítulos, fue la provista por la exitosa plataforma de los folletines. En el siglo XIX, el folletín era un formato que incluía, además, la posibilidad de la colección y su posterior encuadernación. Práctica muy conocida desde mediados de siglo, sobre todo en países como Francia o

11 En efecto, una «Advertencia» al final del pliego avisa: «Deseando satisfacer a los justos deseos con que el comercio anhela por tener una noticia exacta de las entradas y salidas de los barcos en nuestros puertos, y de la cantidad de sus cargamentos [...]; he creído indispensable el insertarla en él, y prevenir al público que para lo sucesivo tendrá en todos los pliegos semanales todas las noticias ocurrentes de este género» (Semanario..., nro. 38, 8 de junio de 2003, p. 301).

12 Al parecer, Cipriano Orden Vetoño era el sinónimo de un conocido colaborador de Vieytes, Pedro Antonio Cerviño. No obstante, dado el sistema de privilegio, las intervenciones podían ondular entre colaboraciones reales, colaboraciones a pedido o totalmente fraguadas. Véanse, a modo de ejemplo, los números 40 («Carta de D. Mariano Frequeriar proponiendo los objetos que debe abrazar este periódico»), 83-85 («Carta IV. De D. Cipriano Orden Vetoño sobre la necesidad de que se establezcan poblaciones en la banda oriental del Río de la Plata»), 86 («Señor editor del Semanario de Buenos Ayres»), o número 137 («Carta de un hacendado de la provincia sobre algunas mejoras fáciles de adoptarse para el acrecentamiento de las posesiones rurales»).

13 Ver, por ejemplo: «Arte de vivir sano y mucho tiempo», extracto del Semanario de Agricultura y Arte italiano (nro. 82, pp. 250-255); las «Conjeturas sobre el origen de las naciones de América, por Fischer, de la Academia de Petersburgo» (nro. 144, pp. 329-332), o el «Discurso del emperador y rey Napoleón, hecho en el Senado el 16 de setiembre de 1805» (nro. 171, pp. 129-131). 
España —hay ejemplos en Chartier (1994), y una lectura pormenorizada del fenómeno en Anne-Marie Thiesse (2000 [1984])—, fue también una modalidad de lectura que ganó - literalmente hablando- su espacio en la prensa latinoamericana, sobre todo avanzada la década de 1840.

La práctica de la encuadernación y la colección económica de literatura se expandió sobre todo con la aparición de la prensa a bajo costo, la prensa callejera o, en la tradición francesa inaugurada por Émile de Girardin y Armand Dutacq, la prensa de a 40 francos, que para principios de esa misma década ya se había instalado como técnica de mercado. La modalidad era en general la inserción tipográficamente diferenciada del resto del periódico, no solo por su ubicación inferior sino también por su paginación particular. Así, por ejemplo, entre los objetos que ofrecían a sus lectores y lectoras los redactores del periódico cubano El Colibrí, no olvidaban ofrecer:

dos pliegos destinados a la inserción en planillas de las mejores novelas, tanto originales como traducidas y que constituyen 32 páginas de lectura extrayéndolas del cuerpo del periódico y encuadernándolas separadamente (para lo cual avisaremos con anticipación el encuadernador que más barato pueda hacerlo) servirán a ir formando una pequeña biblioteca que podrán regalar a sus amigas en bonito tafilete el día de sus natales, ¿porque, qué mejor regalo puede hacerse que el de un libro? (El Colibrí, La Habana, 1847, tomo I, pp. 5-6) ${ }^{14}$.

El periódico — un formato más parecido a la revista ilustrada o magacín- recurre así una práctica que comenzaba a hacerse asidua por entonces, tanto en las principales metrópolis europeas -Francia e Inglaterra, en primer lugar, pero también algunas ciudades o enclaves industriales y financieros de Alemania, España e Italia-, como en las regiones capitales o de mayor desarrollo poblacional de Latinoamérica. El flagelo de los folletines, esto es, la presión que determinadas firmas de escritores folletinistas, más o menos reconocidas -entre ellas, primeramente, las de Dumas y Sue- podían ejercer sobre la producción y circulación literarias en varias partes del mundo, no era ajeno a las preocupaciones de los escritores $y$, mucho menos, de los lectores latinoamericanos. No obstante, hay que decir que esta práctica no solo estaba destinada a la literatura o el drama, también podía utilizarse con otro tipo de textos o documentos, como lo hizo por ejemplo Florencio Varela con su periódico El Comercio del Plata, en el que daba a conocer con ese formato documentos históricos relativos a la conquista y colonización del territorio, con los que pensaba competir

14 El periódico llevaba como subtítulo «Dedicado a las damas». 
con la magnánima empresa editorial del publicista oficial del régimen rosista, Pedro de Ángelis ${ }^{15}$.

Como sea, se trata de un formato específico en el que la lectura, como observó hace tiempo Jesús Martín Barbero (1987), necesariamente debe ser fragmentaria puesto que apunta a captar el interés de un público cuyos hábitos lectores eran (o son) mínimos. En lo que sigue, entonces, propongo repasar brevemente un episodio de este tipo de modalidades de lectura para pensar posibles relaciones entre prensa y públicos lectores.

En mayo de 1852, un lustro antes de la publicación del citado El Colibrí, aparecía en Buenos Aires El Nacional, uno de los primeros diarios longevos de Argentina - que era, por lo demás, continuación de otro que había perdurado unos 20 años, El Diario de la Tarde-. Redactado por Dalmacio Vélez Sarfield, con cuatro páginas y cinco columnas, El Nacional presentaba una disposición tipográfica que anticipaba ya el formato de los diarios sábana del último cuarto de siglo, como La Nación o La Tribuna ${ }^{16}$. Típicamente político, el diario reservaba no obstante un espacio - el inferior, lo que los franceses llaman rez-de-chaussée- para el folletín, buscando de ese modo retener la diversidad de una audiencia a esa altura bastante extendida.

En el mismo espacio dedicado al folletín, el periódico otorgaba un lugar distintivo a la publicación de una Biblioteca de Autores Americanos, lugar que compartía - y con el cual se mimetizaba, de ahí su ambigüedaduno de los folletines publicados en ese primer año, «El vizconde de Bragelonne», de Alexandre Dumas, tercero en la serie de Los mosqueteros ${ }^{17}$. Ahora bien, a diferencia de lo que ocurre con la correcta edición de la Biblioteca de Autores Americanos, los dos primeros folletines que publica El Nacional, esto es, «Los hijos del amor» de Eugène Sue y, precisamente, «El vizconde de Bragelonne» de Dumas son folletines truncos, (mal) seccionados y (mal) dispuestos en la página sin ninguna información que oriente al lector (sobre todo al lector actual, cuya extemporaneidad en las modalidades de lectura decimonónicas oficia como principal obstáculo). La primera entrega de «Los hijos del amor», que aparece con el primer

15 De Angelis había comenzado a publicar a comienzos de 1838 su célebre Colección de obras y documentos relativos a la historia antigua y moderna de las provincias del Río de la Plata. 16 El Nacional se publicó desde el 1 de mayo de 1852 hasta el 28 de agosto de 1893 . Además de Dalmacio Vélez Sarsfield, entre sus colaboradores más destacados en sus distintas épocas figuran: Benito Hortelano, Bartolomé Mitre, Palemón Huergo, Miguel Cané, Gutiérrez, Sarmiento, Avellaneda, Carlos Tejedor, Pedro Echagûe, Belisario J. Montero, entre otros.

17 La biblioteca prevé la posibilidad de la colección: su impresión invertida, con numeración salteada cada cuatro páginas, al igual que un folleto, permite (y anuncia) su encuadernación. En este sentido, la sección reproduce la que Florencio Varela había puesto en circulación en 1845 con su periódico El Comercio del Plata de Montevideo, que se llamó «Biblioteca del Comercio», en la que daba a conocer diversos documentos históricos que conformaban una suerte de archivo histórico-bibliográfico. 
número del periódico, comienza con la primera palabra cortada: «társelo a su padre sería acaso obligada a que se uniese a mí por compromiso»; y varias entregas de ese mismo folletín, también, cortan la frase al final, la cual se reanuda en la próxima entrega, que además no siempre es la del próximo número, como pasa por ejemplo con el número 6, que termina con la frase "Yo no» y continúa no en el 7 sino en el 8, con el anhelado complemento de la oración: «le hablo a Ud. de su gloria militar ni de la eminente posición que ha alcanzado por sus méritos» ${ }^{18}$.

«El vizconde de Bragelonne», por su parte, comienza en esa misma primera entrega directamente por el capítulo 41, páginas 189-192 del formato original de donde es extraído el folletín (las planillas de las que hablaban los redactores de El Colibri), y luego, recién en el número 48 del periódico se reponen las primeras páginas, con su portada y sus primeros capítulos. Imaginar una tipología de lector a partir de estos aislados ejemplos resulta acaso improbable —en efecto: no solo se pone en juego allí el recurso consabido del suspense que la leyenda continuará volvía evidente, sino también aptitudes y modos de uso por parte de un lectorado que lejos estaba de ser homogéneo, etaria o socialmente-; por lo contrario, del tratamiento dispar y desdeñoso de esta sección respecto de otros géneros o textos del periódico surge al menos una presunción: a mediados del siglo XIX la palabra y el espacio folletín han ganado ya un lugar en la prensa sudamericana, al que los redactores de El Nacional evidentemente no quieren desatender; al mismo tiempo, ese lugar se presenta como el más permeable, y por eso mismo el más fácil de adulterar.

Una parte de ese particular tratamiento puede y debería explicarse por el hecho de que El Nacional, como dijimos, era continuidad de otro periódico relativamente longevo de Buenos Aires, el Diario de la Tarde, donde efectivamente esos folletines venían publicándose: Los hijos del amor, de Sue, comenzó a publicarse en el último número del periódico, del 25 de febrero de 1852; «El vizconde de Bragelonne», en cambio, venía publicándose desde mediados de $1851^{19}$. En parte, pero solo en parte. Puesto que

18 Analizando la novela por entregas en España, J. F. Botrel se había encontrado con la misma modalidad de edición, al punto de que folletín y novela por entregas pueden llegar a confundirse. Para Botrel, el corte brusco — incluso de una palabra, como es el caso analizado aquí y en el ejemplo por él citado de la primera entrega de Doña Blanca de Lanuza- funciona como en el cine el detenimiento de la imagen, creando un suspenso que alimenta la demanda lectora (Botrel, 1974, p. 124). Sin desestimar esa función, habría que considerar, no obstante - al menos en los casos de los folletines en la prensa, como el que aquí tratamos-, cierto grado de descuido en la propuesta editorial, descuido o negligencia naturalizada que nos habla, tal vez, de los presupuestos acerca de ese tipo de literatura y, también, de lectores. 19 El folletín de Dumas mereció un suelto de los redactores en el que afirmaban: «Estamos bien seguros del creciente interés con que será leída por nuestros suscriptores, mucho más cuanto que esta obra que ha sido muy recientemente publicada en París con grande 
los cortes abruptos que comentamos - especialmente en el caso de «Los hijos del amor»-y la desorganización del folletín — particularmente el de Dumas, que alcanza sus primeras páginas con la última entrega, es decir que se publica de atrás para adelante- no ocurren solo en o por el pasaje de un periódico a otro.

Una primera hipótesis a discutir sería entonces no tanto que bajo el rótulo folletín la temprana crítica haya englobado una variedad de textos que no respondían al género tipificado en la prensa francesa como roman-feiulleton, sino más bien que esa crítica haya homologado al género rasgos propios de la plataforma periódica, entendida esta como novedoso artefacto de mediación cultural con características propias e igualmente historizables. De esto da cuenta el célebre ensayo de Charles Augustin Sainte-Beuve, «De la littérature industrielle», el cual, publicado casi contemporáneamente a la aparición de las primeras novelas-folletín, estuvo principalmente destinado a atacar esa nueva industria de las letras, la mentada prensa a 40 francos, que proveía la experiencia no tan ilusoria de "vivir de la escritura», lo que Sainte-Beuve denominaba l'invasion de la démocratie littéraire ${ }^{20}$.

En segundo lugar, este tipo de fenómenos parecen indicar que los lectores de la prensa - o determinados grupos de lectores - no leen, en realidad, periódicos: leen textos cuya lógica fragmentaria presupone una práctica de edición popular, personal y a la vez masiva, como es -aún hoy en día en ciertas capas sociales y grupos etarios - la de recortar y encuadernar los textos, práctica que le imprime su propia temporalidad a la continuidad diaria que ofrece el impreso, como si esos compendios de literatura en formato económico (y aquí hay que recordar lo que decían los redactores del periódico cubano respecto de regalar un libro así encuadernado) estuviesen duplicando no ya una demanda de lectura sino más bien un tipo peculiar de consumo.

\footnotetext{
aplauso, no es probable que circule todavía muy generalmente entre nosotros» (Diario de la Tarde, nro. 5891, 10 de mayo de 1851, p. 3).

20 Se publicó en 1839 en la Revue des deux Mondes. En esta famosa diatriba, el folletín recibe indirectamente la condena del crítico. Pues de lo que allí se habla centralmente es del nuevo paradigma industrial y profesional instalado por la prensa. Cualquiera puede llegar a ser un autor, dirá Sainte-Beuve, y dedicará varios párrafos a explicar cómo la ley de imprenta de Martignac (de 1828), al quitar las prebendas estatales favoreció el crecimiento de los avisos comerciales en los periódicos (observará: crecieron las mayúsculas en los anuncios) y cómo esto afectó la relación editor-autor-lector, dado que ahora los editores acostumbran pedir dos volúmenes en $8^{\circ}$, en lugar de uno a fin de extraer más ganancias y, en consecuencia, los escritores terminan por corromper el estilo: escriben palabras vacías, descripciones ociosas, llenas de epítetos redundantes («Les journaux s'élargissant, les feuilletons se distendant indéfiniment, l'élasticité des phrases a dû prêter, et l'on a redoublé de vains mots, de descriptions oiseuses, d'épithètes redondantes : le style s'est étiré dans tous ses fils comme les étoffes trop tendues» [Sainte-Beuve, 1839, p. 685]).
} 


\section{Entre tiendas y basureros de lectura: los que nada leen. ( $A$ modo de conclusión)}

En el número 10 del Telégrafo Mercantil, el primero de los tres periódicos que mencionamos arriba, correspondiente al sábado 2 de mayo de 1801, hay una doble comunicación en forma epistolar: una carta enviada al editor por un antiguo vapuleador del periódico, un tal Patricio Colón, que, ahora arrepentido, se ha vuelto devoto suscriptor, acompañada por otra adjunta que es copia de la que le habría escrito un amigo para convencerlo a este de las ventajas y virtudes del papel periódico. En esta última carta, firmada por un tal Diego Solané, leemos:

No creáis, Amigo, que hablo poéticamente, ni que escribo lo que no siento: observad conmigo los tres puntos enunciados y veréis que o me excedo en las expresiones: $1^{\circ}$, nadie duda que los papeles públicos son la educación de los que no la tienen y la lectura de los que nada leen, ¿qué educación tiene un Patrón de un Barco Inglés y con todo eso le veis entrar aquí siempre cargado de Gazetas y hablar de los asuntos políticos y comerciantes de modo que no haya uno entre vosotros que le conteste? Y ¿qué educación tiene un Peluquero Francés que os estará hablando horas y horas de revolución, o guerra, o de bellas y nobles Artes, teniéndoos tan embobado y silencioso como en otro tiempo un tunante Andaluz que hubiera estado cautivo entre los Argelinos? Pues sabe que todo esto no lo han aprehendido [sic] en otros Libros más que en los Papeles públicos, ni en otras Academias que en los Cafés, o Tabernas; porque el Artesano, La Mujer, el Niño y el Holgazán no son capaces de leer un Libro de volumen; y como estos periódicos son cortos, entretenidos y abundantes en Tiendas, Ante-Salas, y aun Basureros, brindan la curiosidad de las noticias sutiles y deleitables, y por diversión empiezan a leerse; y por otra distracción se leen estas gentes hasta el mismo nombre del Impresor y la licencia del Gobierno, que son los sellos del Papel (Telégrafo Mercantil, nro. 10, 2 de mayo de 2002, p. 77 [el subrayado es mío]).

El fragmento aporta varios elementos para una historia de las modalidades de lectura. En primer lugar, la posibilidad que al parecer otorga el periódico a los anhelos filantrópicos y pedagógicos de las clases ilustradas. Todos parecen aprender de los asuntos públicos a través de esas efímeras páginas, destinadas la mayoría de las veces — según quejas sempiternas - a la envoltura de bagatelas. Ahora bien, en segundo lugar, aunque no menos importante, vale la pena retener el juicio valorativo de esa modalidad de lecturas: los que consumen esos papeles son los que nada leen, es decir, los que no logran familiarizarse con la lectura libresca, sea por desinterés, por competencias lectoras diferenciales, o por condiciones sociales y económicas. Esto presupone un público lector diferencial y a la vez diverso, cuya característica principal sería entonces no pertenecer a 
la esfera de las élites letradas. De hecho, la descripción tipológica de ese público —el artesano, la mujer y el niño- viene a coincidir no casualmente con la categoría de nuevos lectores que ha elucubrado la nueva historia del libro. De modo que, como insisten las descripciones culturales de la lectura, quienes leen periódicos y no libros resumen en buena medida la emergencia de ese nuevo público del siglo XIX, que emerge al parecer -campañas de alfabetización mediante-con el auge de la imprenta mecánica y el uso extendido de la linotipia. Ante esta simbiosis sociológica habría que aducir que lo dicho en el Telégrafo fue escrito en 1802, es decir bien lejos de los procesos de alfabetización masiva con los que suele asociarse el surgimiento de los nuevos públicos lectores. Cabría, entonces, preguntar: ¿se trata de caracterizar esa novedad a partir de un exponencial crecimiento cuantificable de la demanda lectora, tan cuantificable como los índices y estadísticas de la industria editorial o, más bien, de vincular esos datos con la calidad de un proceso de larga data, tan larga como el uso ya relativamente ampliado de los papeles periódicos hacia fines del siglo XVIII? ${ }^{21}$. ¿No debería llamarnos la atención la exacta concordancia de la descripción tipológica de los lectores que nos ofrece el redactor de este periódico de principios de siglo en el Río de la Plata con la categorización sociológica que en la célebre Historia de la lectura en el mundo occidental realiza Martyn Lyons (2001, pp. 539-589) al describir los nuevos lectores - mujeres, niños, obreros - del mediados de siglo europeo? Y, definitivamente: ¿cuán nuevos eran esos nuevos lectores de mediados y fines de siglo en Europa y en Latinoamérica?

No es un dato menor que a esa descripción el ficticio corresponsal del Telégrafo haya agregado la figura del «holgazán». La pereza u holgazanería en la lectura es uno de los rasgos que, como bien ha mostrado Víctor Goldgel (2013), caracterizaría la divisoria de aguas entre lecturas serias y librescas, pero también tradicionales, y lecturas efímeras y folleteriles, aunque también modernas. La oposición entre prensa y literatura subsumía otra entre lectura útil y formativa y lectura banal y disgregativa. Infantes y holgazanes — como la niña de El Curioso-, los que nada leen, sin embargo, son postulados como los nuevos sujetos de la lectura en el siglo XIX.

21 Como se sabe, el alto costo de los periódicos fue un impedimento para esa expansión hasta por lo menos mediados de la década de 1830, cuando Girardin y Dutacq bajaron en Francia a la mitad el costo de la suscripción (de 80 a 40 francos), posibilitando un acceso más fluido a trabajadores manuales, artesanos o comerciantes pobres. No obstante, la calidad de lectura que promovió la prensa periódica — por ejemplo, el éxito que alcanzaron novelas como Pamela, or Virtue Rewarded, de Richardson, tan bien analizado por lan Watt (1968)-, parecería preanunciar un tratamiento extensivo y polifacético del potencial lector con los textos, modalidad que hallaría su momento de eclosión y de ruptura cuando, efectivamente, las tecnologías del impreso posibilitaran un cambio de producción notorio. 
Nuestro propósito ha sido analizar algunos ejemplos de representaciones de lectura en y por la prensa, en un arco temporal lo suficientemente amplio como para poder observar y comparar modalidades de lectura cuyo elemento comunitario era la hoja periódica. De los periódicos tardo-coloniales de principios de siglo, más parecidos a los libros y por ende propuestos como sus sustitutos, a la prensa noticiosa de mediados de siglo en donde los folletines compiten con el fait-divers y la noticia variopinta del día, las experiencias de la lectura periódica - mejor dicho: las representaciones de la prensa periódica de esas experiencias- parecerían indicar, por un lado, que el perfil de los lectores cooptados por el impreso volante es menos novedoso de lo que la bibliografía canónica sobre el tema induce a imaginar.

Por otro lado, si asumimos, con Chartier (1994, p. 36), que los dispositivos escriturarios y formales - es decir, tipográficos - son un factor clave en la construcción de sentido - de los lectores, y a la vez de la historia de la lectura-, parece imprescindible ir más allá de la casuística dominante que abreva en bibliotecas - privadas o públicas - y catálogos de librerías para edificar sus inferencias sobre lectores y lectura en un periodo en el que, como dice el Telégrafo Mercantil de Buenos Aires, comienza a dominar «la lectura de los que nada leen» o, en palabras del historiador Martyn Lyons (2012, p. 305), se imponen aquellos lectores (nuevos) que, sintomáticamente, nunca compran un libro. 


\section{REFERENCIAS BIBLIOGRÁFICAS}

Bolter, J. D. y Grusin, R. (1999). Remediation. Understanding New Media. Cambridge, Massachusetts: MIT Press Edition.

Botrel, J. F. (1974). La novela por entregas: unidad de creación y consumo. En Botrel, J-F. y S. Salaün (Eds.). Creación y público en la literatura española (pp. 111-155). Madrid: Editorial Castalia.

(1998). Teoría y práctica de la lectura en el siglo XIX: el arte de leer. Bulletin Hispanique, 2, pp. 577-590.

Brownlees, N. (2016). «Newes also came by Letters»: Functions and features of epistolary news in English news publications of the seventeenth century. En J. Raymond y N. Moxham (Eds.). News Networks in Early Modern Europe (pp. 394-419). Leiden: Boston.

Cavallo, G. y Chartier, R. (2001). Historia de la lectura en el mundo occidental. Madrid: Taurus y Alfaguara.

Chartier, R. (1994). Libros, lecturas y lectores en la Edad Moderna. Madrid: Alianza Editorial.

Conway, C. (2006). Letras combatientes: género epistolar y modernidad en la Gaceta de Caracas, 1808-1821. Revista Iberoamericana, LXXII (214), 77-91.

Cornejo Polar, A. (1995). La literatura hispanoamericana del siglo XIX: continuidad y ruptura (hipótesis a partir del caso andino). En B. González Stephan, J. Lasarte, G. Montaldo y M. J. Daroqui (Comps.). Esplendores y miserias del siglo XIX. Cultura y sociedad en América Latina (pp. 11-23). Caracas: Monte Ávila.

Lempérière, A. (1998). República y publicidad a finales del Antiguo Régimen (Nueva España). En F. Guerra, A. Lempérière et al. Los espacios públicos en Iberoamérica. Ambigüedades y problemas. Siglos XVIII-XIX (pp. 54-79). México D.F.: Centro Francés de Estudios Mexicanos y Centroamericanos, y Fondo de Cultura Económica.

Lyons, M. (2001). Readers and Society in Nineteenth-Century France. Workers, Women, Peasants. Nueva York: Palgrave.

Lyons, M. (2012). Historia de la lectura y de la escritura en el mundo occidental. Buenos Aires: Editoras del Calderón.

Martín Barbero, J. (1991). De los medios a las mediaciones. Comunicación, cultura y hegemonía. Barcelona: G. Gili.

Martin, H. J. (1994). The History and power of writing. Londres: The University Chicago Press.

Martínez Gramuglia, P. (2010). A la caza de lectores: el Telégrafo Mercantil. Question. Recuperado de http://perio.unlp.edu.ar/ojs/index.php/question/index 
(2012). Nuevos textos, nuevos (y viejos) lectores: la representación del público en los periódicos de 1801 a 1810. En G. Batticuore y S. Gayol (Comps.). Tres momentos de la cultura argentina: 18101910-2010 (pp. 25-40). Buenos Aires: Prometeo.

McKenzie, D. F. (1985). Bibliography and the Sociology of Texts. Londres: British Library.

Sainte-Beuve, C A. (1839). De la littérature industrielle. Revue des deux Mondes, XIX, pp. 675-691.

Thiesse, A. M. (2000). Le roman du quotidien. Lecteurs et lectures populaires à la Belle Époque. París: Éditions du Seuil.

Torné, E. (2001). La mirada del tipógrafo. El libro entendido como una máquina de lectura. Litterae. Cuadernos sobre Cultura Escrita, I, pp. 145-177.

Watt, I. (1968). The Rise of the Novel. Studies in Defoe, Richardson and Fielding. Londres: Penguin Books. 